Cambridge Archaeological Journal

http://journals.cambridge.org/CAJ

Additional services for Cambridge Archaeological Journal:

Email alerts: Click here

Subscriptions: $\underline{\text { Click here }}$

Commercial reprints: Click here

Terms of use : Click here

Roman Imperialism and Local Identities, by Louise Revell, 2009. Cambridge:

Cambridge University Press; ISBN 978-0-521-88730-4 hardback £42 \& US\$74; xiv+221 pp., 33 b\&w ills.

Andrew Gardner

Cambridge Archaeological Journal / Volume 20 / Issue 02 / June 2010, pp 269 - 270

DOI: 10.1017/S0959774310000296, Published online: 10 June 2010

Link to this article: http://journals.cambridge.org/abstract S0959774310000296

How to cite this article:

Andrew Gardner (2010). Cambridge Archaeological Journal,20, pp 269-270 doi:10.1017/S0959774310000296

Request Permissions : $\underline{\text { Click here }}$ 
Roman Imperialism and Local Identities, by Louise Revell, 2009. Cambridge: Cambridge University Press; ISBN 978-0-521-88730-4 hardback $£ 42$ \& US\$74; xiv+221 pp., 33 b\&w ills.

\section{Andrew Gardner}

One of the chief problems confronting the archaeologist of the Roman empire is that of scale. For a field often accused (and not without reason) of narrow parochialism it is nonetheless one which encompasses a wide expanse of space and time, and a diverse range of social institutions. Understanding the articulation of larger-scale imperial processes with smaller-scale community and individual narratives has proven a challenge, frequently met with reduction of the former to the concept of 'Romanization', and straightforward application of this to a small sample of the latter. Recent scholarship has increasingly shown, on theoretical and empirical grounds, that this simply will not do as a way of interpreting the complexity of the empire, and Louise Revell's book is an admirable demonstration of the way forward. Focusing on urban communities, but moving deftly between different scales and axes of comparison, Revell constructs a convincing account of the multiple experiences of 'being Roman'. In its attention to the everyday practice of inhabiting the urban places of the empire, this book also makes a significant contribution to the wider archaeology of architecture and space.

Revell's study is necessarily constrained to a particular period - primarily the earlier part of the second century $\mathrm{AD}-$ and to a part of the empire. In the latter case though she takes the relatively unusual step of exploring case studies from two regions - Britain and Spain - rather than only one, and this allows for many profitable comparisons. While of course further contrasts might be drawn with towns of the eastern empire, there is sufficient variation within the regions covered to highlight the similarities and differences in material practice which underpin the interpretations of identity offered. Identity is of course a key theme and the book's preface and introductory chapter briefly review previous approaches to 'Roman-ness' - largely encompassed by the paradigm of 'Romanization'. Revell rightly chooses not to dwell too long on this retrospective, covered in detail elsewhere, and instead moves forward by highlighting key aspects of the structurationist social theory to be deployed and of the material to be studied. The latter is tackled at the general level of approaches to public architecture and inscriptions, and in the particular detail of the towns providing the main examples. The introduction does a very good job of defining the goals of the book, though a little more on certain aspects of identity - specifically the nature of ethnicity - might have clarified one or two points of the argument later on (an issue I will return to below). Nonetheless, the chief insights of structuration theory are well captured here and, more importantly, are successfully worked through in the rest of the book.

CAJ 20:2, 269-70 $\quad$ C 2010 McDonald Institute for Archaeological Research doi:10.1017/S0959774310000296
This comprises four main chapters, covering different axes of the relationship between particular communities and the wider empire. Chapter 2, 'Living the Urban Ideal', focuses upon the concept of urbanism as an ideology. Covering key debates on the role of towns in Roman imperialism, Revell explores some of the unifying threads of urban experience - the importance of boundaries, the contrast between town and country, and legal and administrative matters - but also highlights their subtly different manifestations in four detailed examples. The next two chapters examine important institutional forces within the empire - the authority of the emperor, and the organization of religious activity - again highlighting commonalities and divergences in the interactions between individual communities and these structural sources of power. Chapter 3's discussion of the Roman emperor is less focused on individual emperors as agents and more upon the role of the emperor, manifest through image, cult, political patronage and historical consciousness. Thus we get a good sense of how different urban communities experienced a seemingly somewhat abstract idea of imperial rule in a very tangible way. Similarly, in Chapter 4, the diverse religious institutions of the empire are explored primarily in their enaction, through the evidence for different kinds of ritual activity in different towns. The importance of this lies in getting away from a simplistic discourse of what is more or less 'Roman' about Roman religion, and again examples are used very well here to create dynamic and lively images of the activities going on in towns. The final substantive chapter links together some of these preceding aspects through the lens of another structure: status differentiation. Here we see the cityscapes of the empire from different viewpoints, with the contrast between the most prominent in the evidence - that of elite males - and those of others used to good effect. Comparing the use made of different kinds of public space by different kinds of people effectively emphasizes the ways in which structures of gender, wealth and citizenship were shaped by the people living them out on an everyday basis. The book concludes with a short summary further highlighting the key tension between similarity and difference in Roman urban life that each chapter has demonstrated.

Overall, then, the book presents a very successful implementation of practice theory in Roman archaeology which offers substantial new insight into the diversity of experience in Roman towns. In doing so, it brings to life the public architecture of these towns in a genuinely exciting fashion, and deserves to be influential beyond Roman studies. There are just a couple of areas where the argument might have been strengthened. The book's focus is on the public sphere, but in a Roman town this might overlap considerably with the domestic, and yet this does not really appear. Another incongruity comes in Revell's reference to Roman identity as an ethnic identity, which begs a definition of ethnicity never elaborated. This is important because one of the key dynamics of Roman imperialism seems to be the transformation of a Roman ethnic identity into something else - a cultural identity that can sit alongside an individual's identification with the place in the empire that they have come from and define 
them more by legal status and by some shared practices. More attention to this issue would do better justice to the book's core concern with the relationship between multiple identities. It would also have been worthwhile for Revell to develop Chapter 6 a little more by coming back to some of the key points of structuration theory and highlighting how the case studies have demonstrated the utility of these. Nonetheless, these points do not detract from Revell's significant achievement in breathing life into the remains of Roman towns, and inhabiting them with a diverse range of people by exploiting in new ways evidence which has rarely been used to its full potential. This book provides a sound demonstration of how the complex business of integrating the large and the small-scale in Roman archaeology should proceed.

\author{
Andrew Gardner \\ Institute of Archaeology \\ University College London \\ 31-34 Gordon Square \\ London \\ WC1H OPY \\ UK \\ Email: andrew.gardner@ucl.ac.uk
}

